\title{
CASOS CLÍNIICOS
}

\section{TUMOR DE KRUKENBERG}

CON PRIMARIO GASTRICO

ENMASCARADO POR HIPEREMESIS

GRAVIDICA

KRUKENBERG TUMOR WITH PRIMARY GASTRIC ADENOCARCINOMA MASKED BY HYPEREMESIS GRAVIDARUM

Heredia Carrasco C, López Tobaruela JM, Librero Jiménez M, Herrador Paredes M, García Montero MJ

Hospital Universitario Virgen de las Nieves. Granada.

\section{Resumen}

Presentamos el caso de una mujer joven sin enfermedades relevantes previas con hiperemesis gravídica diagnosticada desde la semana 8 de embarazo, en la que finalmente se llega a un diagnóstico completamente distinto al persistir la sintomatología tras el parto.

Palabras clave: adenocarcinoma gástrico, tumor de Krukenberg, hiperemesis gravídica.

\section{CORRESPONDENCIA}

Clara Heredia Carrasco

Hospital Universitario Virgen de las Nieves

18014. Granada

clara.heredia121@gmail.com

Fecha de envío: 13/06/2020

Fecha de aceptación: 05/07/2020

\section{Abstract}

We report the case of a young woman without prior relevant diseases diagnosed with hyperemesis gravidarum from week 8 of pregnancy, in which a completely different diagnosis is determined as the symptoms persist after delivery.

Keywords: gastric adenocarcinoma, Krukenberg tumor, hyperemesis gravidarum.

\section{Introducción}

Dado que el diagnóstico de hiperemesis gravídica es clínico, consideramos de interés este caso para incidir en la importancia del diagnóstico diferencial y detectar aquellas pacientes que por sintomatología de alarma o datos analíticos, precisen exploraciones complementarias. 


\section{Descripción}

Mujer de 35 años con vómitos desde la semana 8 que ceden con tratamiento médico. Hasta la fecha de parto múltiples visitas en urgencias por vómitos, dolor abdominal hipogástrico y pérdida de peso, con datos analíticos de colestasis e hipertransaminasemia y ecografía abdominal donde se aprecia engrosamiento antropilórico (Figura 1) con adenopatías, todo ello de probable etiología inflamatoria y aumento bilateral de ovarios (Figura 2) compatible con edema ovárico bilateral o luteomas secundarios a la gestación. Serología de virus hepatotropos negativa.

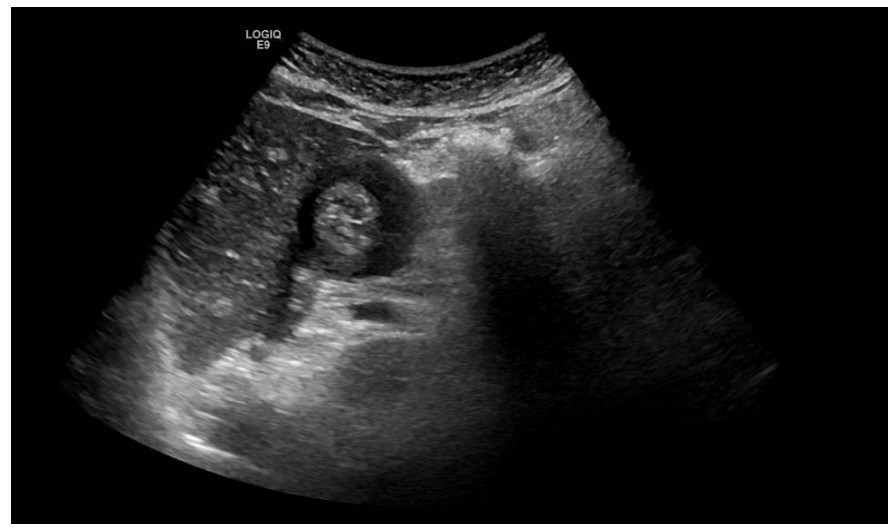

Figura 1

Engrosamiento antro-pilórico en ecografía.

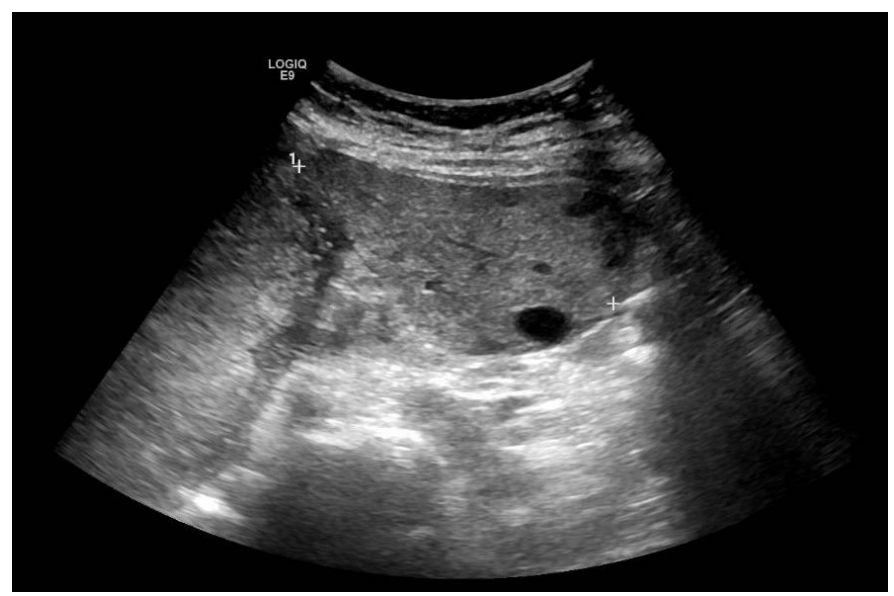

Figura 2

Engrosamiento ovárico en ecografía.

Antecedentes de dispepsia, dos gastroscopias previas en 2010 y 2014 con lesión submucosa antro-pilórica de $4 \mathrm{~mm}$ sin otras alteraciones y erradicación de Helicobacter pylori.

Tras el parto los síntomas no remiten y desarrolla intolerancia a la ingesta. Se realiza endoscopia digestiva alta que objetiva lesión gástrica extensa de aspecto neoplásico, con biopsias de adenocarcinoma infiltrante de patrón difuso (células en anillo de sello) y TAC toraco-abdomino-pélvico que concluye tumor de Krukenberg con primario gástrico y metástasis ovárica bilateral con carcinomatosis peritoneal.

La paciente pasa a cargo de Oncología, recibiendo quimioterapia paliativa actualmente con segunda línea.

\section{Discusión}

El adenocarcinoma gástrico en su variante difusa tiene una edad media diagnóstica de 50 años y presenta un comportamiento clínico más agresivo que la variante intestinal (la más frecuente), mientras que las náuseas y vómitos se presentan en un $40-60 \%$ de las gestantes, la mayoría respondiendo bien a modificaciones de dieta y fármacos para alivio sintomático. Sólo un pequeño porcentaje $(0,25 \%$ $0,5 \%)$ sufren una verdadera hiperemesis gravídica que no responde al tratamiento, y se caracteriza por una progresiva deshidratación, pérdida de peso y en algunos casos asocian hipertransaminasemia o colestasis.

No podemos olvidar que una mínima parte de casos responden a patología orgánica distinta y precisan de un adecuado diagnóstico diferencial, sobre todo aquellos con signos de gravedad y escasa respuesta al tratamiento.

Nuestra paciente presentaba criterios clínicos de hiperemesis gravídica y dificultó mucho el diagnóstico correcto que los síntomas de la neoplasia eran superponibles y se iniciaron durante la gestación. No obstante, el dolor hipogástrico y los hallazgos ecográficos pudieron habernos orientado a otras etiologías.

\section{Bibliografía}

1. Tian YT, Ma FH. Diagnosis and treatment strategy of gastric cancer with ovarian metastasis. Chinese Journal Of Oncology 2019;41(3):178-182.

2. Yan D, Du Y, Dai G, Huang L, Xu Q, Yu P. Management of synchronous Krukenberg tumors from gastric cancer: a single-center experience. Journal of Cancer 2018;9(22):4197-4203

3. Cho JH, Lim JY, Choi AR, Choi SM, Kim JW, Choi SH, Cho JY. Comparison of Surgery Plus Chemotherapy and Palliative Chemotherapy Alone for Advanced Gastric Cancer with Krukenberg Tumor. Cancer Research and Treatment 2015;47(4):697-705.

4. Hussain N, Selvakumani N, Afadapa F, Amu O. Pregnancy and gastric cancer: diagnostic and treatment dilemma. BMJ Case Reports 2018.

5. Song MJ, Parks YS, Song HJ, Park SJ, Ahn JY, Choi KD, Lee GH, Jung HY, Yook $\mathrm{JH}, \mathrm{Kim}$ BS. Prognosis of pregnancy-associated gastric cancer: an age-, sex-, and stage-matched case-control study. Gut Liver 2016;10(5):731-8. 